\title{
Pulmonary effects of cocaine use
}

\begin{abstract}
Cocaine is a powerful central nervous system stimulant extracted from the leaves of Erythroxylon coca, a native plant of the Andean and Amazon regions in South America. Cocaine has multiple effects on the lungs, both acute and chronic. Effects of cocaine to the lungs depend on the route of administration (oral, nasal, intravenous), dose size, frequency of exposure, and presence of associated substances like heroin, talc or marijuana. These effects include barotrauma; airway injury; asthma; pulmonary edema; pulmonary hemorrhage; "crack lung", eosinophilic lung disease; bronchiolitis obliterans, organized pneumonia, interstitial lung disease; pulmonary hypertension; emphysema; both infectious and aspiration pneumonias; and tumors. The most commonly encountered respiratory symptoms include cough productive of dark sputum (carbonaceous material), chest pain, dyspnea, hemoptysis, wheezing, and exacerbation of asthma.
\end{abstract}

Keywords: cocaine, alveolitis, hemoptysis and pulmonary hemorrhage, crack lung, eosinophilic lung disease, bronchiolitis obliterans
Volume 4 Issue 2 - 2017

\section{Joyce A Akwe}

Department of Medicine, Emory University School of Medicine, USA

Correspondence: : Joyce A Akwe, Department of Medicine, Atlanta Veterans Affairs Medical Center, Emory University School of Medicine,Atlanta GA, USA, Email joyce.akwe@emory.edu

Received: March 19, 2017 | Published: May 31, 2017

\section{Introduction}

Cocaine is an alkaloid found in the leaves of Erythroxylon coca, commonly known as coca. Erythroxylon coca is a native plant of the Andean and Amazon regions in South America. In the mid-19th century the inhabitants of the Andes chewed the leaves to ward off fatigue, hunger and thirst, to enhance endurance, and to promote a sense of wellbeing. Cocaine was used as a local anesthetic in eye, ear and throat surgery. ${ }^{1}$ Cocaine is a powerful central nervous system stimulant and has very complex activity, both through central and peripheral pathways. The local anesthetic properties of cocaine derive from its ability to stabilize cell membranes and block neuronal sodium channels. It also has potent sympathomimetic and central nervous system stimulant effects due to interference with the reuptake of catecholamines and serotonin thereby preventing nervous transmission. ${ }^{2,3}$ Cocaine is sold on the street, mixed with similarlooking substances like lidocaine, talcum powder or sugar. Cocaine is generally consumed in freebase form or smoked as "crack". It can be absorbed via intranasal, intravenous or vaginal routes in the hydrochloride form or by massaging the gums in coca paste form (prepared using solvents like kerosene and gasoline). It can be smoked either in pipes or cigarettes. ${ }^{1}$ Cocaine hydrochloride is a heat-labile fine white powder that can be inhaled nasally or injected intravenously but cannot be smoked. Freebase, a lipid-soluble, heat-stable, form that can be smoked is produced from cocaine hydrochloride. When Cocaine hydrochloride is boiled in water and baking soda, it forms a precipitate which is filtered or extracted with ether or alcohol into an irregular crystal which is the freebase form. The free base form looks like a rock thus commonly called the rock. When the rock is heated, it makes a characteristic "crack" sound thus it is also known as crack. ${ }^{4-7}$ "Crack lung" refers to a syndrome of diffuse alveolar damage and hemorrhagic alveolitis that occurs within 48 hours of crack cocaine use. It is characterized by acute respiratory symptoms like shortness of breath or cough. Crack lung is associated with diffuse alveolar hemorrhage or occasionally eosinophilia on bronchoscopy. Diffuse alveolar damage and hyaline membrane formation is commonly found in biopsy or autopsy specimens of cocaine users who present with crack lung. ${ }^{8-10}$ In this article, we discuss the common effects of cocaine to the lungs and emphasize on the need for a thorough history in the diagnosis of the effects of cocaine to the lungs. Most of the patients present with common signs and symptoms that could be found in other medical conditions, but the key to the correct diagnosis is in a thorough history.

\section{Effects of cocaine on the lungs}

The pulmonary effects of cocaine could be acute or chronic. Effects of cocaine on the lungs depend on the route of administration (oral, nasal, intravenous), dose size, frequency of exposure, and presence of associated substances like heroin, talc or marijuana. Cocaine causes multiple types of injury to the lungs as noted on (Table 1). The combustion product of cocaine is relatively small in size and so can migrate to the alveoli within a short period of time. Cocaine use causes damage in the entire airway from the bronchus to the alveolar region of the lung. The main symptoms that cause cocaine users to present to the emergency rooms are cardiopulmonary symptoms. Cough, wheezing and dyspnea are the most common complaints. ${ }^{11}$ Dark sputum is very particular in these patients. The dark sputum is due to massive quantities of carbon pigments which are also often found in the bronchoalveolar lavage (BAL) of patients with a history of crack cocaine abuse. Many addicts collect this black material and re-smoke it with more crack. The inhalation of these impurities lead to extensive accumulation of large amounts of intracellular (macrophages) and extracellular carbon pigment. ${ }^{12}$ Stridors from edema of the arytenoids, epiglottis, and vocal cords have been reported after use of free-base cocaine. ${ }^{13}$ In many cocaine users with lung symptoms, radiologic examination demonstrate patchy alveolar infiltrates affecting the upper and lower lobes of both lungs. ${ }^{14}$ Fourteen to twenty five percent of patients who present to the emergency department in urban hospitals with non-traumatic chest pain have detectable levels of cocaine or cocaine metabolites in the urine and $6 \%$ will have enzymatic evidence of myocardial infarction. . $^{15,16}$ 
Table I Commonly encountered lung injuries and symptoms in cocaine users

\begin{tabular}{|c|c|}
\hline Commonly encountered lung injury & $\begin{array}{l}\text { Commonly } \\
\text { encountered symptoms }\end{array}$ \\
\hline $\begin{array}{l}\text { Pneumothorax pneumopericardium, or } \\
\text { subcutaneous emphysema }\end{array}$ & $\begin{array}{l}\text { Cough with carbonaceous } \\
\text { sputum }\end{array}$ \\
\hline Airway damage & Chest pain \\
\hline $\begin{array}{l}\text { Asthma Exacerbation and Bronchospasms in } \\
\text { Non asthmatics }\end{array}$ & Shortness of breath \\
\hline $\begin{array}{l}\text { Bronchiolitis Obliterans with Organized } \\
\text { Pneumonia and Bronchiolitis }\end{array}$ & Hemoptysis \\
\hline Pulmonary Edema & Fever \\
\hline Pulmonary Emphysema & Wheezing \\
\hline \multicolumn{2}{|l|}{ Hemoptysis and Pulmonary Hemorrhage } \\
\hline \multicolumn{2}{|l|}{ Hypersensitivity Pneumonitis and Alveolitis } \\
\hline \multicolumn{2}{|l|}{ Infection and Aspiration Pneumonia } \\
\hline \multicolumn{2}{|l|}{ Pulmonary Hypertension } \\
\hline \multicolumn{2}{|l|}{ Tumors } \\
\hline
\end{tabular}

The use of crack cocaine may lead to pneumothorax, pneumomediastinum, or subcutaneous emphysema. ${ }^{14}$ These complication are all thought to be related to barotrauma to the lungs of crack cocaine smokers. ${ }^{17}$ Pneumothorax and pneumomediastinum are commonly related to cocaine inhalation or smoking, in the freebase or crack forms. ${ }^{2,18-22}$ Barotrauma is a result of coughing or intense Valsalva's maneuver intentionally performed to heighten the effect of the drug. Valsalva's maneuver leads to a sudden increase in intrabronchial and intra-alveolar pressure with subsequent alveolar rupture and air penetration in the pulmonary interstitium. ${ }^{17}$ The free air can dissect the peribronchial connective tissue in the mediastinum, pericardium, pleural cavity and subcutaneous tissues, resulting in pneumopericardiumand subcutaneous emphysema. ${ }^{22,23}$ Other mechanisms explaining the barotrauma include: deep inhalation followed by mouth-to-mouth positive pressure applied by an accomplice. ${ }^{17,24}$ Also, the long term injection of contaminated substances results in inflammation and sclerosis of the veins. Once the peripheral veins are no longer accessible because of sclerosis, intravenous users aim at either the internal jugular vein or the subclavian vein. This can be complicated by laceration of the lung apex leading to Pneumothorax..$^{25}$

\section{Airway damage}

Mucosal damage is common in patients who inhale cocaine Habitual nasal inhalation of cocaine may cause mucosal lesions from the nasal orifices, nasal wall, sinuses, turbinates, and palate. Lesions to the nose and upper airways may extend to the perichondrium, with ischemic necrosis and destruction of the septal cartilage or lateral nasal wall. ${ }^{26}$ Chemical byproducts transported in the smoke of freebase cocaine or intra-tracheal combustion of highly inflammable solvents used in the production process of freebase cocaine can cause thermal injury and consequently tracheal stenosis.

\section{Asthma exacerbation and bronchospasms in non- asthmatics}

Cocaine use causes asthma exacerbation in patients with asthma. Cocaine use, whether in the form of smoking or nasal inhalation is well known to precipitate bronchospasm and wheezing, especially in patients with a previous history of asthma. Smoking or inhaling cocaine precipitates bronchospasm in both asthmatics and nonasthmatic users. In one study, cocaine was shown to precipitate bronchospasm and thus wheezing in $32 \%$ of habitual crack users. ${ }^{27}$ In fact, wheezing has been reported in $32 \%$ of habitual crack users during the period of use. Smoked cocaine causes acute bronchoconstriction, with an onset within 3 minutes of use and duration of at least 15 minutes in healthy individuals with no history of asthma. Cocaine users have increase in airway resistance. ${ }^{28}$ Smoked cocaine base, but not systemically administered cocaine hydrochloride, provokes acute bronchoconstriction that is probably mediated by local airway irritation. This could account for reports of crack-induced wheezing even in non-asthmatic users. ${ }^{28}$ Bronchospasm caused by cocaine use can be very severe and can progress to respiratory failure and death especially in people who already have asthma. ${ }^{29,30}$

\section{Bronchiolitis obliterans and organized pneumonia}

Respiratory failure with bronchiolitis obliterans and organized pneumonia has been reported in free base cocaine users. These findings were documented at open lung biopsies of young crack cocaine smokers. ${ }^{17,31}$ Lung biopsies of these patients reveal areas of fibroblastic plugs occupying at the terminal bronchioles and alveolar spaces. Cocaine inhalation stimulates interstitial fibrosis in the airways and metaplastic bronchiolar epithelium. The bronchioles of cocaine users develop thick muscles leading to a very aggressive and distinct form of diffuse lung disease..$^{32}$ Interstitial pneumonitis or interstitial fibrosis has been reported in $38 \%$ of autopsies of patients with a positive toxicology test for cocaine.$^{33}$ Interstitial fibrosis progresses to the development of respiratory insufficiency with a significant mortality rate.

\section{Pulmonary edema}

Pulmonary edema has been reported in both intravenous cocaine users and crack cocaine smoking. In fact, pulmonary edema has been demonstrated in $77 \%-85 \%$ of cocaine-related deaths in autopsy series. ${ }^{33,34}$ Pulmonary edema in cocaine users may be due to damaged pulmonary capillary endothelium with increased permeability or it may be cardiogenic in nature. ${ }^{35}$ Cocaine use cause myocardial infarction, arrhythmias, congestive heart failure and endocarditis. These may be contributing factors to the development of pulmonary edema in cocaine users. ${ }^{36}$

\section{Pulmonary emphysema}

Pulmonary emphysema in cocaine users is characterized by destruction of the alveolar wall as well as permanent enlargement of airspaces distal to the terminal bronchioles. About $2 \%-4 \%$ of intravenous drug abusers have upper lobe predominant emphysema. These findings are typically found in young males who use intravenous drugs. ${ }^{37,38}$ Severe bilateral upper lobes peripheral bullous changes have been reported. Lung biopsy specimens demonstrate intra and extravascular foreign bodies, thrombosis, and areas of inflammation adjacent to the emphysematous bullae..$^{39}$ 


\section{Hemoptysis and pulmonary hemorrhage}

Within the last decade, alveolar hemorrhage has been described as a complication of cocaine use. ${ }^{17,18,40-42}$ Hemoptysis has been reported in $6 \%-26 \%$ of crack users. The use of freebase cocaine can lead to diffuse alveolar hemorrhage with hemoptysis and massive life threatening bleeding that may require surgery. ${ }^{40}$ Pulmonary hemorrhage may be due to rupture of bronchial or tracheal submucosal blood vessels, or from injury to the alveolar-capillary membrane. ${ }^{27,28}$ Bouchi J et al. ${ }^{43}$ suggested that cocaine triggers alveolar hemorrhage by direct damage to the pulmonary vasoconstriction and alveolar cells. ${ }^{43}$ Cocaine induced thrombocytopenia has also been suggested as a possible mechanism of alveolar hemorrhage. ${ }^{17}$ Occult pulmonary hemorrhage is very common in asymptomatic cocaine smokers. This is a common finding in patients who die from an overdose of either cocaine or heroin. ${ }^{8,17,44}$ Bailey et al. ${ }^{33}$ reviewed lung histopathology results from 52 autopsies with positive toxicology tests for cocaine from the medical examiner's offices in Dallas and Austin, TX. They found acute hemorrhage in $58 \%$ of the biopsies, chronic hemorrhage in $40 \%$, interstitial pneumonitis/fibrosis, $38 \%$ congestion, $88 \%$ and intra-alveolar edema, $77 \%$. There were no significant differences in the changes found based on the method of use. ${ }^{33}$ Murrey et al ${ }^{34}$ found occult lung hemorrhage at autopsy of about $30 \%$ of people who died suddenly from cocaine overdose. ${ }^{34}$

\section{Hypersensitivity pneumonitis and alveolitis}

Cocaine inhalation can lead to pneumonitis and interstitial fibrosis. ${ }^{33}$ Pulmonary and peripheral eosinophilia are common findings after inhalation of cocaine..$^{8,17,45}$ Lung tissue specimens obtained from patients with crack lung reveal both interstitial and alveolar infiltration of eosinophils, with deposition of $\operatorname{IgE}$ and alveolar hemorrhage. Acute lung injury and diffuse alveolar damage involving all lung regions has been frequently reported. ${ }^{46,47}$ Bailey et al. ${ }^{33}$ found pneumonitis with the thickening of alveolar sputum, and infiltrates of neutrophils, macrophages, lymphocytes and eosinophils. Pulmonary fibrosis was also noted with the presence of pneumocystis hyperplasia type II. ${ }^{33}$ Bronchial alveolar lavage (BAL) of patients with cocaine induced hypersensitivity pneumonitis usually have pulmonary eosinophilia and up to $40 \%$ of peripheral eosinophilia. ${ }^{45}$ Eosinophilic "empyema" associated with eosinophilic pneumonitis secondary to crack cocaine smoking has also been reported in the setting of peripheral eosinophilia and eosinophilia in pleural fluid. ${ }^{48}$ High levels of vascular endothelial growth factor, a leak mediator that is present in eosinophils, and increased levels of interleukins (IL-5, -6 , and -8 ) have been identified in the pleural fluid. These findings suggest a potential role in the development of the effusion. ${ }^{48,49}$

\section{Pulmonary hypertension}

Pulmonary hypertension has been reported in cocaine users, but the mechanism is still unclear. Vascular abnormalities have been reported in the absence of foreign particle embolization in crack cocaine users. Medial hypertrophy of both small and medium-sized pulmonary arteries has been demonstrated in up to $20 \%$ of autopsies of victims of cocaine-related death. ${ }^{34}$ This may be the mechanism responsible for pulmonary hypertension. Crack cocaine users may develop pulmonary infarction secondary to severe local vascular spasm and in situ thrombosis. ${ }^{50}$ The vasoconstrictive effect on the pulmonary vasculature can mimic pulmonary embolism in a crack cocaine smoker who presents with chest pain. Intense pulmonary artery vasospasm may provoke a misleading high-probability ventilation-perfusion lung scan. ${ }^{51}$ Pulmonary hypertension may also be related to alveolar hemorrhage..$^{52}$

\section{Infectious and aspiration pneumonia}

Smoking Crack cocaine damage alveolar macrophages and thus severely limits their ability to kill bacteria and to prevent tumor cell growth. Septic pulmonary embolism and communityacquired pneumonia are among the most common pulmonary complications seen in intravenous drug abusers $(23.5 \%$ and $19.6 \%$ of cases, respectively. ${ }^{53}$ Cocaine users may develop altered mental status ranging from psychosis to coma thus increasing their risk for aspiration pneumonia.

\section{Tumors}

Cocaine smoking just like tobacco and marijuana has been found to produce a carcinogenic effect on the bronchial epithelium. Chronic irritation with repeated vasoconstriction and chronic inflammation from irritants and solvents could be contributing factors. ${ }^{54}$ Histopathologic abnormalities such as basal cell hyperplasia, stratification, increased nuclear-cytoplasmic ratio, and squamous cell metaplasia are more frequently found in the lungs of individuals who smoke crack cocaine. Cocaine use appears to lead to fewer significant bronchial mucosal alterations than marijuana or tobacco when smoked alone and does not add to the changes associated with marijuana. When smoked together with tobacco, however, cocaine appears to augment the bronchial injury caused by tobacco smoking. ${ }^{55}$

\section{Conclusion}

Illicit drug use is in the rise and cocaine use is no exception. Very few studies have been conducted on the effects of cocaine to the lung. Based on these few reports and available studies; cocaine has potentially devastating effects on the lungs. A thorough history is indispensable to the diagnosis and management of cocaine induced lung injury. Lung imaging of patients with damage due to cocaine use are largely nonspecific. Most of the findings could also be attributed to other causes, making a thorough history of cocaine use the most powerful tool in the diagnosis and consequently appropriate management.

\section{Acknowledgments}

None.

\section{Conflicts of interest}

Author declares that there is no conflict of interest.

\section{References}

1. Terra Filho M, Yen CC, Santos Ubiratan de Paula, et al. Pulmonary alterations in cocaine users. Sao Paulo Medical Journal. 2004;122(1):2631 .

2. Benowitz NL. Clinical pharmacology and toxicology of cocaine. Pharmacol Toxicol. 1993;72(1):3-12.

3. Madden JA, Powers RH. Effect of cocaine and cocaine metabolites on cerebral arteries in vitro. Life Sci. 1990;47(13):1109-1114.

4. Nadeem S, Nasir N, Israel RH. Löffler's syndrome secondary to crack cocaine. Chest. 1994;105(5):1599-1600.

5. Laposata EA, Mayo GL. A review of pulmonary pathology and mechanisms associated with inhalation of freebase cocaine (crack). Am J Forensic Med Pathol. 1993;14(1):1-9. 
6. Thadani PV. NIDA conference report on cardiopulmonary complications of "crack" cocaine use: Clinical manifestations and pathophysiology. Chest. 1996;110(4):1072-1076.

7. Nappo SA, Galduróz JCF, Noto AR. Uso do “crack" em São Paulo: fenômenoemergente? [Crack use in São Paulo city: an emergent phenomenon?]. Rev ABP-APAL. 1994;16(2):75-83.

8. Forrester JM, Steele AW, Waldron JA, et al. Crack lung: an acute pulmonary syndrome with a spectrum of clinical and histopathologic findings. Am Rev Respir Dis. 1990;142(2):462-467.

9. McCormick M, Nelson T. Cocaine-induced fatal acute eosinophilic pneumonia: a case report. WMJ. 2007;106(2): 92-95.

10. Devlin RJ, Henry JA. Clinical review: Major consequences of illicit drug consumption. Crit Care. 2008;12(1):202.

11. Del Bono E, O’Brien K, Murphy R. Lung sound abnormalities in cocaine free-basers. Subst Abus. 1989;10:201-208.

12. Greenebaum E, Copeland A, Grewal R Blackened bronchoalveolar lavage fluid in crack smokers. A preliminary study. Am J Clin Pathol. 1993;100(5):481-487.

13. Silverman RS, Lee-Chiong TL, Sherter CB. Stridor from edema of the arytenoids, epiglottis, and vocal cords after use of free-base cocaine. Chest. 1995;108(5):1477-1478.

14. Restrepo CS, Carrillo JA, Martínez S, et al. Pulmonary Complications from Cocaine and Cocaine-based Substances: Imaging Manifestations. Radio Graphics. 2007;27(4):941-956.

15. Hollander JE, Todd KH, Green G, et al. Chest pain associated with cocaine: An assessment of prevalence in suburban and urban emergency departments. Ann Emerg Med. 1995;26(6):671-676.

16. Hollander JE, Hoffman RS, Gennis P, et al. Prospective multicenter evaluation of cocaine-associated chest pain. Cocaine Associated Chest Pain (COCHPA) Study Group. Acad Emerg Med. 1994;1(4):330-339.

17. Haim DY, Lippmann ML, Goldberg SK, et al. The pulmonary complications of crack cocaine. A comprehensive review. Chest. 1995;107(1):233-240

18. Heffner JE, Harley RA, Schabel SI. Reações pulmona resdevidasao abuso de drogasilícitas. In: Cooper JAB, editor. Clínicas de doençaspulmonares. Brazil: Rio de Janeiro; 1990. p. 151-159.

19. Shesser R, Davis C, Edelstein S. Pneumomediastinum and pneumothorax after inhaling alkaloidal cocaine. Ann Emerg Med. 1981;10(4):213-215.

20. Aroesty DJ, Stanley RB, Crockett DM. Pneumomediastinum and cervica emphysema from the inhalation of "free based" cocaine: Report of three cases. Otolaryngol Head Neck Surg. 1986;94(3):372-374.

21. Eurman DW, Potash HI, Eyler WR, et al. Chest pain and dyspnea related to "crack" cocaine smoking: value of chest radiography. Radiology. 1989;172(2):459-462.

22. Leitman BS, Greengart A, Wasser HJ. Pneumomediastinum and pneumopericardium after cocaine abuse. Am J Roentgenol. 1988;151(3):614.

23. Ettinger NA, Albin RJ. A review of the respiratory effects of smoking cocaine. Am J Med. 1989;87(6):664-668

24. Sullivan TP, Pierson DJ. Pneumomediastinum after freebase cocaine use AJR Am J Roentgenol. 1997;168(1):84.

25. McCarroll KA, Roszler MH. Lung disorders due to drug abuse. J Thorac Imaging. 1991;6(1):30-35

26. Trimarchi M, Gregorini G, Facchetti F, et al. Cocaine-induced midline destructive lesions: clinical, radiographic, histopathologic, and serologic features and their differentiation from Wegener granulomatosis. Medicine (Baltimore). 2001;80(6):391-404.
27. SuhlJ, Gorelick DA. Pulmonary function in male freebase cocaine smokers. Am Rev Respir. 1988;137:A488.

28. Tashkin DP, Kleerup EC, Koyal SN, et al. Acute effects of inhaled and i.v. cocaine on airway dynamics. Chest. 1996;110(4):904-910.

29. Rubin RB, Neugarten J. Cocaine-associated asthma. Am J Med. $1990 ; 88(4): 438-439$

30. Rao AN, Polos PG, Walther FA. Crack abuse and asthma: a fatal combination. N Y State J Med. 1990;90(10):511-512.

31. Patel RC, Dutta D, Schonfeld SA. Free-base cocaine use associated with bronchiolitis obliterans organizing pneumonia. Ann Intern Med. 1987;107(2):186-187.

32. Churg A, Myers J, Suarez T, et al. Airway-centered interstitial fibrosis: a distinct form of aggressive diffuse lung disease. Am J Surg Pathol. 200;28(1):62-68.

33. Bailey ME, Fraire AE, Greenberg SD, et al. Pulmonary histopathology in cocaine abusers. Hum Pathol. 1994;25(2):203-207.

34. Murray RJ, Smialek JE, Golle M, et al. Pulmonary artery media hypertrophy in cocaine users without foreign particle microembolization. Chest. 1989;96(5):1050-1053.

35. Cucco RA, Yoo OH, Cregler L, et al. Non-fatal pulmonary edema after "freebase" cocaine smoking. Am Rev Respir Dis. 1987;136(1):179-181.

36. Schwartz BG, Rezkalla S, Kloner RA. Cardiovascular effects of cocaine Circulation. 2010;122(24):2558-2569.

37. Goldstein DS, Karpel JP, Appel D, et al. Bullous pulmonary damage in users of intravenous drugs. Chest. 1986:89(2):266-269.

38. O’Donnell AE, Pappas LS. Pulmonary complications of intravenous drug abuse: experience at an inner-city hospital. Chest. 1988;94(2):251-253.

39. Gurney JW, Bates FT. Pulmonary cystic disease: comparison of Pneumocystis carinii pneumatoceles and bullous emphysema due to intravenous drug abuse. Radiology. 1989;173(1):272-31.

40. Godwin JE, Harley RA, Miller KS, et al. Cocaine, pulmonary hemorrhage, and hemoptysis. Ann Intern Med. 1989;110(10):843.

41. Murray RJ, Smialek JE, Golle M, et al. Pulmonary artery media hypertrophy in cocaine users without foreign particle microembolization Chest. 1989;96(5):1050-1053.

42. Walek JW, Masson RG, Siddiqui M. Pulmonary hemorrhage in a cocaine abuser. Chest. 1989;96(1):222.

43. Bouchi J, el Asmar B, Couetil JP, et al. Hémorragie alvéolaire après inhalation de cocaïne. Alveolar hemorrhage after cocaine inhalation. Presse Med. 1992;21(22):1025-1026.

44. Murray RJ, Albin RJ, Mergner W, et al. Diffuse alveolar hemorrhage temporally related to cocaine smoking. Chest. 1988;93(2):427-429.

45. Oh PI, Balter MS. Cocaine induced eosinophilic lung disease. Thorax 1992;47(6):478-479.

46. Kissner DG, Lawrence WD, Selis JE, et al. Crack lung: pulmonary disease caused by cocaine abuse. Am Rev Respir Dis. 1987;136(5):1250 1252.

47. Kon OM, Redhead JB, Gillen D, et al. "Crack lung” caused by an impure preparation. Thorax. 1996;51(9):959-960.

48. Strong DH, Westcott JY, Biller JA, et al. Eosinophilic "empyema" associated with crack cocaine use. Thorax. 2003;58(9):823-824.

49. Horiuchi T, Weller PF. Expression of vascular endothelial growth factor by human eosinophils: upregulation by granulocyte macrophage colony-stimulating factor and interleukin-5. Am J Respir Cell Mol Biol. 1997;17(1):70-77. 
50. Delaney K, Hoffman RS. Pulmonary infarction associated with crack cocaine use in a previously healthy 23-year-old woman. Am J Med. 1991;91(1):92-94.

51. Ramachandaran S, Khan AU, Dadaparvar S, et al. Inhalation of crack cocaine can mimic pulmonary embolism. Clin Nucl Med. 2004;29(11):756-757.

52. Russell LA, Spehlmann JC, Clarke M, et al. Pulmonary hypertension in female crack users. Am Rev Respir Dis. 1992;145: A717.
53. Baldwin GC, Tashkin DP, Buckley DM, et al. Marijuana and cocaine impair alveolar macrophage function and cytokine production. $\mathrm{Am} \mathrm{J}$ Respir Crit Care Med. 1997;156(5):1606-1613.

54. Barsky SH, Roth MD, Kleerup EC, et al. Histopathologic and molecular alterations in bronchial epithelium in habitual smokers of marijuana, cocaine, and/or tobacco. J Natl Cancer Inst. 1998;90(16):1198-1205.

55. Fligiel SE, Roth MD, Kleerup EC, et al. Tracheobronchial histopathology in habitual smokers of cocaine, marijuana, and/or tobacco. Chest. 1997;112(2):319-326. 